\title{
Deep Coal Power Foundation Excavation of Rock Burst Hazard PENG Linjun ${ }^{1}$

\author{
${ }^{1}$ Academician Pioneering Park, Dalian University, Dalian, Liaoning 116622, China \\ apenglinjun969@sina.com
}

Keywords: Deep coal seams; Tunneling rock burst; Structural mechanics model; Stress control

\begin{abstract}
Rock burst is one the world's worst coal mine disaster, rock burst accident-prone nature and severity of injuries to become one of the focus of attention, rock burst is an extremely complex dynamic phenomena, is home to cutting-edge research topics of major coal mine safety. Rock burst prevention is currently the mining sector following the gas disaster to be studied and solved another major disaster. This paper analyzes the causes of bumping and achieve the conditions proposed deep excavation rock burst classification model, focusing on the power rock burst accident prediction and control of information.
\end{abstract}

\section{Introduction}

Practice has proved that burst in coal mines and mining major accidents and stress field surrounding rock movement (including stress magnitude, changes in distribution), directly or indirectly related.

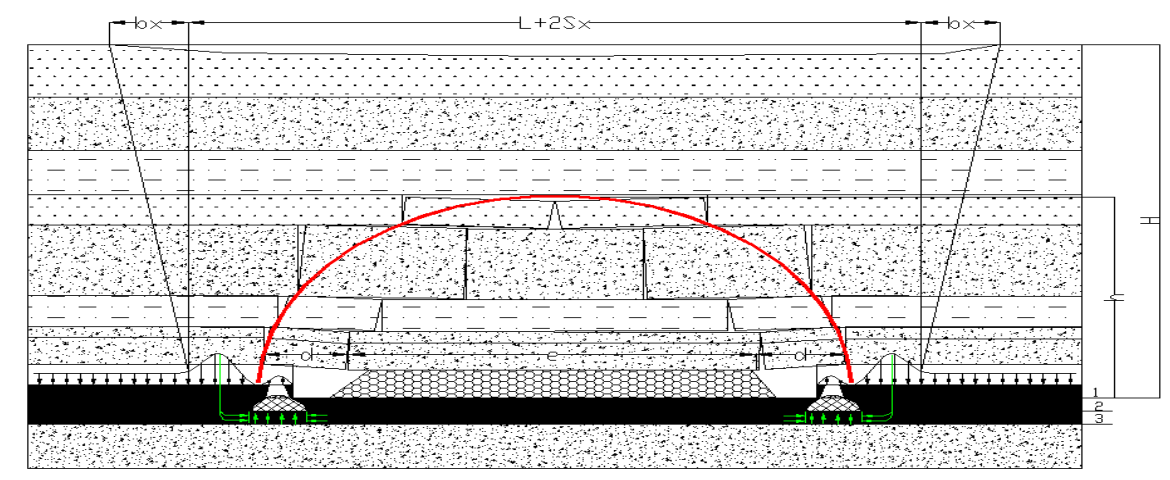

Fig. 1 Heading impact mechanical model diagram mine pressure occurs

Can be seen from Figure 1, if we can correctly determine the scope of mining for the destruction of the overlying strata movement, including rock from already caving (instability) destruction of arch rock and water flowing fractured zone constituted and spread ground movement and settlement participation range, predict and control the associated rockburst and will have a foundation. Similarly, the right to determine the scope of the stress field due to the movement of the rock face in mining participate directly related to the scope, including the stress field within the scope of the destruction of the rock movement in the arch of the decision, and the overlying strata movement overall gravity stress field stress the scope of distribution, to achieve a stable internal stress digging in the field and continue to maintain the roadway mining face, the relevant heading of bumping major accidents can be effectively controlled. 


\section{Deep seam heading rock burst conditions occur and damage characteristics}

Driving rock burst occurred in the process of advancing Heading Face. The excavation in the original coal roadway impact stress field conditions occur:(1) high seam strength ( $>1.5$ ), low moisture content $(<3 \%)$, brittle fracture occurs when the pressure that "there is tendency to impact damage." (2) seam thickness is large, generally more than $2 \mathrm{~m}$.Limit the impact of the destruction. (3) roadway (including coal and roof and floor) in the stress reaches. This limit is reached at a single gravity stress field conditions "critical mining depth", usually more than $700 \sim 800 \mathrm{~m}$. For the existence of the original stress tectonic stress field in the mining depth of more than $500 \sim 600 \mathrm{~m}$ thick coal seam excavation, that there may be an accident of top coal impact damage.



Fig. 2 Mining stress field in driving map

Heading stress field of rock burst occurred condition: mining depth over 400 meters, the peak pressure in the supporting parts of tunneling inevitable. In a stable internal stress field tunneling does not occur. Mining height (seam thickness) greater, the smaller the probability of occurrence.

Deep excavation damage stress field characteristics: high roof and floor strength, impact extrusion between two coal wall, roof and floor-strength low-floor vibration damage occurs.

\section{Deep impact stress distribution model mine pressure occurs}

Tunneling-induced rock burst, vibration resistance to impact damage, not only in driving source - near the face, but also in the entire energy spread compression (highly stress concentration) region all roadways and workplaces. Storage capacity of greater compression elastic range, higher energy levels, strength and sheer scope of impact damage will also be greater. Therefore, on the basis of the relevant figure out the size of the stress field in the stress distribution and the formation and development of the law, the maximum to avoid the high pressure can build up in the area of roadway excavation and placement is the key to control rock burst damage and the corresponding accident.

For a single mining gravity stress field, it should be absolutely avoided during storage and high compression coal pillar stope support pressure energy peak area roadway. It should seek to maximize the mining area mountains, open stoping drift Cut and arranged in advance to have stabilized after stope "internal stress field", the realization of roadway in a stable internal stress field. Figure 3 shows the next three surface coal gob condition, and three open stoping drift excavation Cut possible locations. 


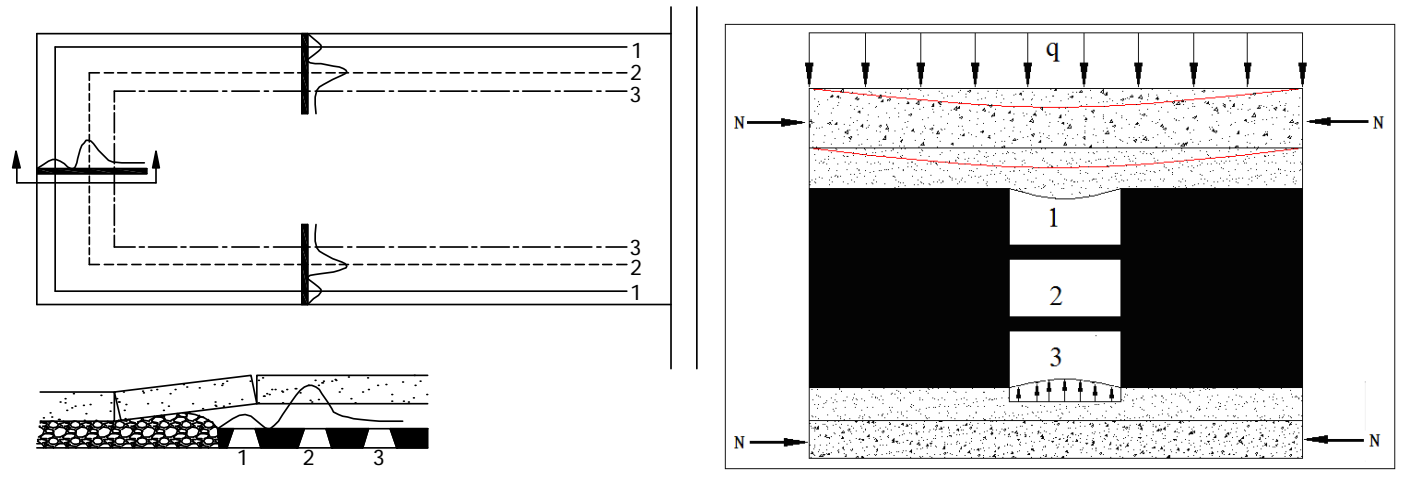

Figure :one for low stress field excavation, two representatives of the high stress field excavation, three representatives of the stress field of the original excavation.

Fig3 Digging in stress distribution

\section{Deep excavation rock burst main categories}

When driving rock burst occurred, will be accompanied by a strong shock impact will depend on the surrounding rock roadway conditions and the nature of the variation of compressive stress occurs in different forms of damage. Driving with the correct (broken rock) methods and forms of support, can effectively exclude the impact to crush people and other major accidents disasters. The following practical results as a basis for deepening the study. Heading Face rockburst prediction and control research classification model shown in Figure 1.

Fig.1 The disaggregated model of rockburst during driving

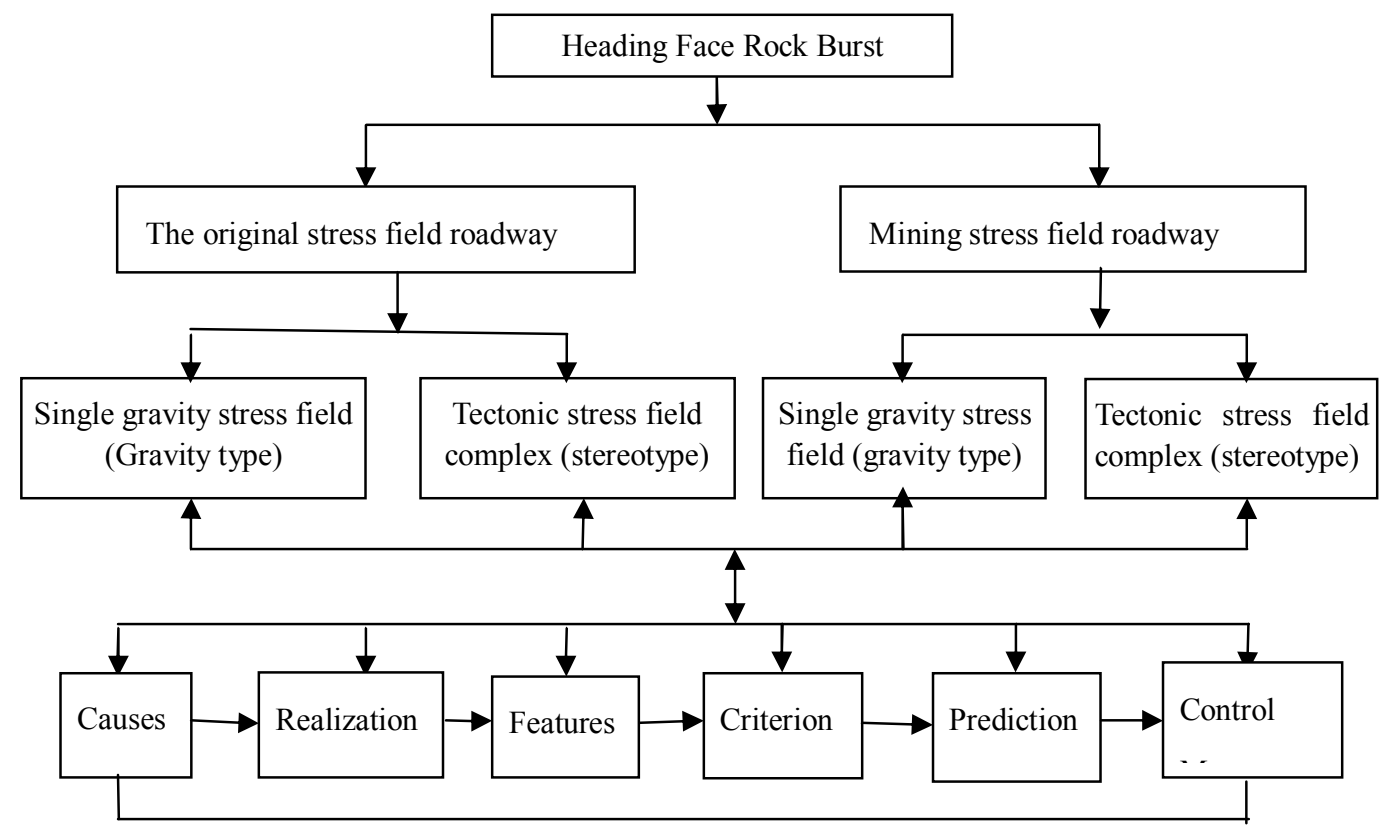

The coal should be taken to soften, millisecond secondary seal blasting detonators reduced energy induced, long-distance remote broken coal. The use of steel mesh to help support the consolidation of two ways beneficial to control rock burst occurrence of the accident. The use of roof bolting with mesh, and the use of anchor reinforcement measures in low-intensity backplane help control hazards related accidents.have rockburst in dangerous roadways, using a simple framework supporting not only can not control the impact of the destruction occurred, contrary shock and vibration damage and instability caused by momentary demolition destruction frame 
shoring easy to produce personal injury.

\section{Conclusions}

Control of bumping incidents including control rock burst occurred and potentially destructive disaster in two ways. The former is to first figure out the cause of rock burst occurred and the conditions to achieve. As a basis for reasonable "anti-red" program design, including the use of reasonable mining method, mining program and mining correct parameters to the possibility of bumping reduced to a minimum. The latter at a time and place that the impact of possible ground pressure by taking reliable technology economy measures, including reducing the impact energy and reduce impact damage spread range of technical measures, as well as mining and roadway safety precautions Face workspace etc. prevent casualties and equipment damage and other damage accidents.

\section{Acknowledgements}

This Research Was Supported by State Key Laboratory for Geo Mechanics and Deep Underground Engineering, China University of Mining \& Technology (No.SKLGDUEK1420); This research is sponsored by the National Natural Science Foundation of China (No.51479195,51374046);Liaoning Provincial Science and Technology Department talents fostering projects (No.201501948)

\section{References}

[1] He Manchao, Xie Heping, Peng Suping etc. Research in deep mining rock mechanics and engineering disaster control. Deep Mining basic theory and engineering practice. Science Press .2006,15 32

[2] Song Zhenqi. editor of Practical Mining pressure control [M]. China Mining University Press, 1998

[3] Zhao Yixin, Jiang Yaodong, Tian Supeng rockburst formation energy dissipation characteristics of [J] coal, 2010,35 (12): $1979 \sim 1983$.

[4] Qi Qingxin, sinus forest name of bumping Theory and Technology [M] Beijing: China University of Mining and Technology Press, 2008.

[5] S. Y. Wang et al. Analytical and Numerical Study on the Pillar Rockbursts Mechanism. Rock Mechanics and Rock Engineering. 2006,39(5): 445-467.

[6] Ross C A,JEROME DM. Moisture and strain rate effects on concrete strength [J]. ACI Mater J,1996(33): 293-300. 